\title{
STLDIES IN THE INFLUENCE OF ABNORMAL POSITION UPON THE MOTOR IMPULSE.
}

BY DR. CHARLES THEODORE BURNETT.

\section{The Japanese Illusion and the Mirror Illusions.}

The experiments that form the basis of the following report are the first of a series designed to open a new approach to the psycho-physics of the motor impulse, by way of the modifications that occur in the control of a limb when placed in unusual positions. The particular investigations of this paper are concerned with the direction of the impulse as shown in the control of the fingers when the hands are placed in unusual positions; concerned, in other words, with the ability to move a given finger at command.

We shall consider first the Japanese illusion. It occurs when, with arms crossed, the hands are clasped thumbs down, and are turned thumbward till they point up. If an onlooker, pointing to one of the fingers, asks the man thus situated to move it, the latter is frequently unable to do so, moving, if anything, some other finger. Of the experimental conditions, it need be said only that the hands were unclasped after every movement in many series; and that either the wrists and neighboring parts of the arms were concealed by a cloth wrapped about them, or the observer was covered with a sort of apron fastened about the neck and having an opening with edges drawn together by an elastic cord. Through this opening the clasped fingers could be thrust while most of the remainder of the hand was concealed. The purpose of these precautions was to preserve as long as necessary an illusion that yields pretty readily to experience of the situation. In the first form of this experiment the finger to be moved was indicated visually to the observer by pointing, whereupon the latter was to make the morement as quickly as possible. No attempt was made to eliminate the possible influence of the crossing of hands, whether right over left or left over right. But here and through- 
out, except in a single instance noted in its place, each finger (including thumbs) was as often required to move as is any other. The order of choice was irregular.

Table I.

JAPANESE ILLUSION.

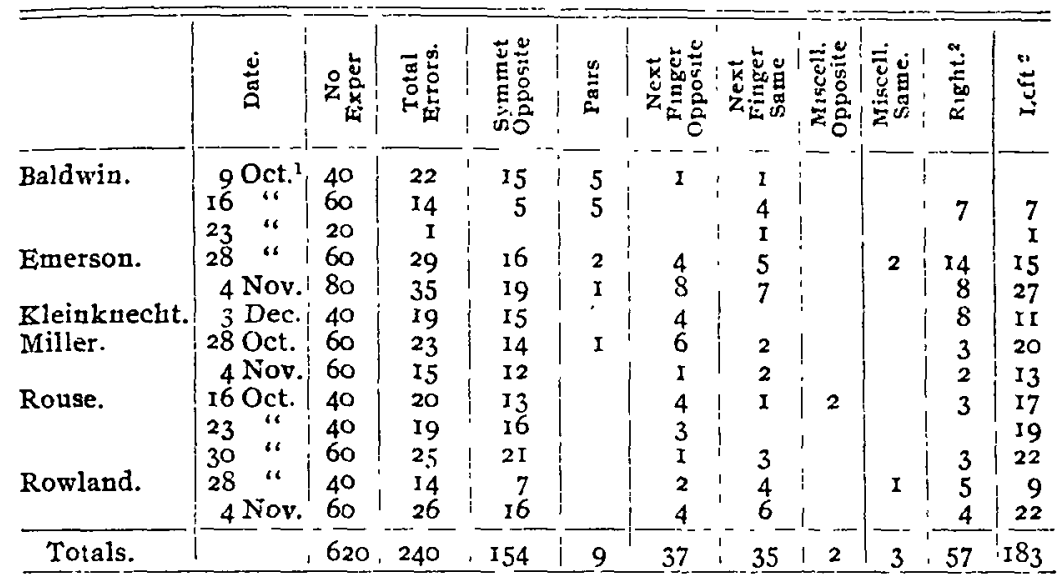

\section{Results.}

I. The disturbance in the direction of the motor impulse is rather large, as shown by the proportion of errors to the number of experiments.

2. In some cases adjustment to the abnormal position is not long in occurring. Miller and especially Baldwin show this. The latter, in a short test made after those recorded, showed entire readjustment.

3. The erroneous movements far more frequently occur in the finger symmetrically opposite than in any other. Following at a long distance are erroneous movements in the next fingers opposite and the next fingers on the same side. Errors of other types are few and scattering.

4. The errors occur far more frequently when the movement is to be made with the left hand than when it is to be made with the right. No observer shows a contrary tendency, though some exhibit none.

1 Omitted from totals because fingers were not equally employed.

2In these columns througbout the tables are recorded the number of failures for the hand in question. 
5. With hands in normal position, palms up, there are practically no errors.

6. When a finger is touched as well as pointed out, there is almost never an error.

7. When the eyes of the observers were closed and the finger to be moved was indicated by naming it, the following results were obtained:

\begin{tabular}{|c|c|c|c|}
\hline & No Exp. & Errors Symmet Opp. & Errors Miscell \\
\hline $\begin{array}{l}\text { Baldwin. } \\
\text { Emerson. } \\
\text { Kleinknecht. } \\
\text { Miller. } \\
\text { Rouse. } \\
\text { Rowland. }\end{array}$ & $\begin{array}{l}40 \\
30 \\
30 \\
60 \\
40 \\
40\end{array}$ & $\begin{array}{l}0 \\
0 \\
0 \\
9 \\
8 \\
7\end{array}$ & $\begin{array}{l}5 \\
0 \\
4 \\
4 \\
5 \\
0\end{array}$ \\
\hline
\end{tabular}

Here is a great reduction in the illusion. That this is not due in all cases merely to a growing familiarity with the situation is shown by the results of Emerson. Work in connection with this illusion previous to the present test had not occurred for four weeks. The day after this test the old conditions were restored and the illusion was back as strong as ever. The results of Miller show about as much illusion as in one of the sets of experiments recorded against him in Table I. Hence it seems possible that his confusion lay in his kinæsthetic knowledge of where his fingers were located. This confusion nearly disappeared for him when the hands were laid palm downward on the table pointing away from the body, while the other conditions of auditory stimulus and closed eyes were maintained. The presence of a weakened illusion with Rouse is perhaps connected with the fact that he visualized his hands. This Miller did not do.

\section{Conclusions.}

I. It appears from (6) and (7) above that the illusion lies in the visual, not in the kinæsthetic, experience of abnormal position, though one observer presents a possible exception.

2. The large excess of erroneous movements made with the finger symmetrically opposite shows how large a factor in the direction of the motor impulse is the visual peculiarity of a given finger. The motor current appropriate to that peculiarity is 
started; but the element contributed by visual position diverts it to the wrong hand.

3. Why, it may be asked, does the visual experience of abnormal position divert the current far more frequently to a finger on the opposite hand than to another on the same hand? A glance at the hands in the position appropriate to the illusion will show that the roots of the fingers lie on the side opposite to the arm to which they belong; that the right-hand fingers point from the left to the right, and the left-hand fingers from the right to the left. This is just the reverse of what is true when the hands are clasped in the usual way. Going upon the basis of procedure in the normal situation, the observer in the unusual position moves the finger that really lies on the side on which the given finger appears visually to lie. This process of reasoning is, of course, wholly in the mind of the experimenter. For the observers the process is so mechanical that they are obliged to consider seriously when asked how they obey a given command. The usual reply is that they simply sec what is wanted and then do it. The movement appears to follow directly upon the visual cue. It is not to be denied that the observers feel in some measure confused in this unusual position and occasionally feel almost unable to move any finger. The attitude of hasty attention that favors so many geometrical-optical illusions seems to be the best one in the present instance. The confusion soon yields far enough to permit a movement that is not merely spasmodic.

4. Why any correct movements at all? They become possible by a new adjustment to the new position-a recognition that the right-hand fingers point from the left and the left-hand fingers from the right. Some effort may be required to substitute the new visual cue for the old, and, when effort fails, habit steps into control. The new adjustment may be but partly successful and a wrong finger moved on the correct side. The mistakes of this sort give the second maximum of errors.

5. Is there any psychological account to be given of the second focus of errors in Table I., viz., in movements of the fingers next to the correct one whether on the same or the opposite hand? This is possible if in some way it could be shown that 
the two fingers resembled each other. The middle and ring fingers resemble each other more than do any other two adjacent members, and the thumb and forefinger least of all. Here is the way in which the errors were distributed among adjacent pairs :

$$
\begin{array}{ll}
\text { Thumb and fore-finger }=19 & \text { Middle and ring }=25 \\
\text { Fore- and middle-finger }=19 & \text { Ring and little }=10
\end{array}
$$

There is no ground here for basing the error wholly on mutual resemblance, though to this it may at times be due. We seem driven to a purely physiological account.

6. That the second greatest tendency to error should involve moving a finger next to the correct one, while yet this tendency cannot be due in general to resemblances, suggests that what would be the habitual course of the motor impulse is preventing somehow a wider divergence in its actual course. It does not appear otherwise why the errors should not be more widely distributed.

7. The source of superiority in control of the right over that of the left hand does not at once appear. For movements so simple in the normal position such a difference does not exist.

TABLE II.

JAPANESE IILUSION.

\begin{tabular}{|c|c|c|c|c|c|c|c|}
\hline & $\begin{array}{c}\text { No. } \\
\text { Exper. }\end{array}$ & Ertors & $\begin{array}{l}\text { Symmet. } \\
\text { Opposite }\end{array}$ & $\begin{array}{c}\text { Next } \\
\text { Finger } \\
\text { Opposite. }\end{array}$ & $\begin{array}{c}\text { Next } \\
\text { Finger } \\
\text { Same. }\end{array}$ & Right.' & I.eft. ${ }^{1}$ \\
\hline $\begin{array}{l}\text { Emerson. } \\
\text { Kleinknecht. }\end{array}$ & $\begin{array}{l}40 \\
40\end{array}$ & $\begin{array}{l}23 \\
14\end{array}$ & $\begin{array}{l}\text { I5 } \\
\text { I4 }\end{array}$ & 8 & & $\begin{array}{r}14 \\
6\end{array}$ & $\begin{array}{l}9 \\
8\end{array}$ \\
\hline Rouse. & 40 & 5 & 3 & 2 & & & 5 \\
\hline Rowland. & 40 & 16 & II & 3 & 2 & 2 & 14 \\
\hline Totals. & 160 & $5^{8}$ & 43 & I3 & 2 & & \\
\hline
\end{tabular}

Left hand crossed over right.

Right hand over left.

\begin{tabular}{l|c|c|c|c|c|c|r}
\hline Emerson. & 40 & 19 & 14 & 5 & & 6 & 13 \\
Kleink necht. & 40 & 17 & 16 & 1 & & 3 & 14 \\
Rouse. & 40 & 12 & 10 & 1 & 1 & 5 & 7 \\
Rowland. & 40 & 18 & 14 & 3 & I & 5 & 13 \\
\hline Totals. & 160 & 66 & 54 & 10 & 2 & & \\
\hline
\end{tabular}

${ }^{1}$ Totals henceforth are not recorded in these columns because of the divergence among observers. 
One objective factor not thus far controlled might be involved in this result. The abnormal position studied here can be obtained by crossing right hand over left or left over right. There is frequently a difference in strain in the two wrists; and the hand and wrist of more intense sensation might possibly be under better control. So much is at least suggested by the lessening of error when the control was of the auditory-kinæsthetic type. Or we might indeed find the reverse to be true. Table II. gives us the results of experiments similar to the preceding, but designed to show the effects, if any, of the method of crossing. Baldwin is omitted in this test because the illusion had nearly disappeared for him.

\section{REsUlts.}

I. There are still many more failures in case of a commanded movement with the left hand than with the right. There is but one observer whose results suggest any influence of the method of crossing. No simple relation is apparent between the presence or absence of a feeling of strain, as reported by the observers, and this particular tendency to error. So the cause must still be sought.

2. The distribution of errors is like that in Table I, except that all scattering errors have disappeared and very few are found in the next finger on the same side.

\section{Mirror Experiments.}

In the following sets of experiments the abnormal position was attained by the use of a mirror, occasionally of two. The mirror space inverts the spaces of the real world in a direction perpendicular to the plane of the mirror; so that fingers in front appear to be in the rear, and those to the right lie apparently on the left; and vice ricrsa. A direct view of the fingers was prevented by a broad collar of cardboard. After a few of these experiments had been made it was thought best, to the end of preserving the illusions in force, that the observers either close their eyes or look away after noting the finger to be moved, and then complete the movement. They were forbidden, however, to develop any new sources of information after closing the 
eyes. The general conduct of the experiments was as before except that the thumbs were not used, since in some positions they could not be conveniently interlocked with neighboring members.

The results are so arranged in the tables as to show the extent to which the errors follow the mirror reversal. To illustrate - when the hands are clasped palms up and the line of the interlocked fingers is perpendicular to the plane of the mirror, the forefingers which are really farthest from the body will in the mirror space be nearer the real body, while the little fingers, which are really nearer, will in the mirror space be farther away. If now the observer be directed by pointing to move a forefinger and he thereupon move the little finger or ring finger, that error would show that the movement followed upon the risual cue, the mirror space being regarded not otherwise than as real space. An erroneous movement of fore- or middlefinger for either ring- or little-finger will be classified thus; not so fore- for middle-finger or vice versa, nor ring- for littlefinger. In other words, the eight fingers, being interlocked, are divided by a median line into two sets. The finger wrongly moved must not lie in the same half with the finger pointed out, if the error is to be classed as following the mirror reversal. If it does lie in the same half, one cannot say that the error is not due to the same cause. But by arbitrarily limiting the evidence to the more striking cases, a preponderance of these will make our conclusions much stronger.

By way of introduction we may notice here the character of the errors occurring in the attempt to trace with a pencil the outlines of figures that cannot be seen directly but only as reflected in a mirror. Henri ${ }^{1}$ reports such experiments. The present results confirm his in all essential respects. (I) When asked to trace the outlines of a rectangle whose side was parallel to the plane of the mirror, all seven observers succeeded easily, though in four a false start in the opposite direction was noted when they began to trace the lines perpendicular to the mirror. This is the space relation that the mirror reverses, and

1 'Revue generale sur le sens musculaire.' V. Henri. Année Psych., V., pp. $504-8$. 
the wrong movement thus conformed to the visual cue. The tracing of the diagonals in this position was almost, if not quite, an impossibility for four observers, movements being made at right angles to the one desired, i. $c$., in a direction conforming to that of the reflected line. For the other three observers the movement was easy enough except at high speeds, where an occasional error similar to the foregoing betrayed the tendency usually held in check by the successful adjustment to the new conditions. The reaction seems to involve the association of a new kinæsthetic complex with a given visual impression as soon as the reflected image shows that the movement is being made in the right direction. These two types of reaction suggest two types of brain function - the one where the organic paths already formed chiefly determine the direction of the motor impulse, and the presence of an element common to the new and the old is sufficient to draft the entire current into the old channels; while in the other type all the new elements contribute in determining the direction of the motor impulse. When the corner of the rectangle was toward the mirror, the difficulty in drawing sides and diagonals respectively was reversed; but in kind was like the earlier error. (4) If a more complicated figure, such as a six-pointed star, be set for outlining, the difficulty increases, though in the case of one or two observers all

TABLE III.

Mirror front. Supination. Fingers Crossed in Palms.

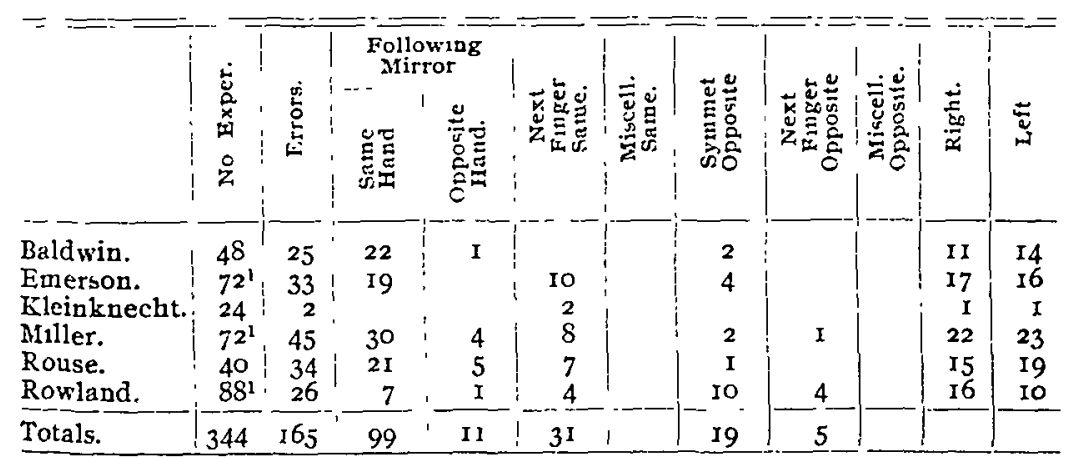

1 Results of several days combined. Tendency in the separate series the same as that in total except in Rowland's failures to right and left. The excess of right-hand failures is due to the results obtained at a single sitting. 
the new adjustments desired throughout this experiment were made with ease.

Table IV.

Mirkor Front. Pronation. Fingers Crossed over Backs of Hands.

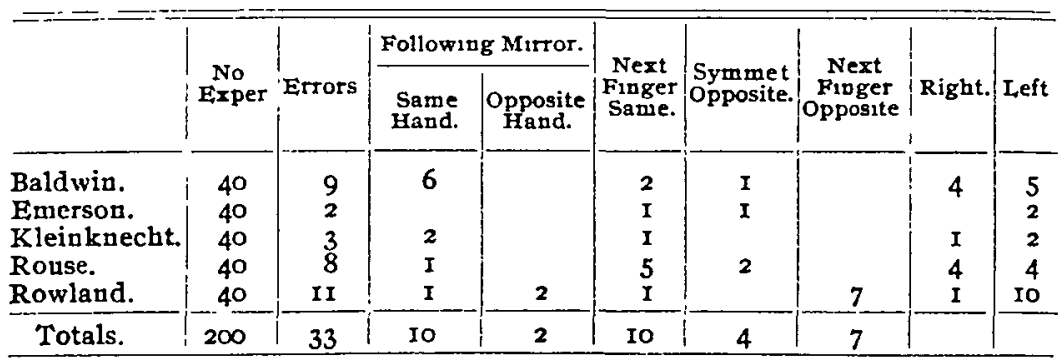

Of the special conditions governing the experiments of Tables III. and IV. it need only be said that in both cases the line of the fingers was kept perpendicular to the plane of the mirror, so far as comfort would allow. The fingers were so clasped in the work of Table IV. that the left forefinger always came next to the body; while for the experiments of Table III. the left little finger occupied that place, except in a part of the tests with Emerson and Rowland.

\section{REsUlts.}

I. The disturbance in the direction of the motor impulse is very markedly shown in Table III., though one observer is almost unaffected.

2. The influence of the visual factor appears in the fact that more than two thirds of the errors follow the mirror reversal.

3. There is no prominent tendency toward an excess of failures in one hand over the other. For most of the observers it is quite absent.

4. Nearly one fifth of the errors consists in a movement of a finger of the opposite hand. This is not due to any inversion effected by the mirror, so far as one can see.

5. The bulk of all the errors not directly accounted for by the mirror reversal consists in the wrong movement of the symmetrically opposite finger and of the next finger on the same side.

6. Under the conditions of Table IV. the illusion has greatly decreased. It is to be especially noted that the causes operative 
in the former case to produce errors that the mirror reversal could not dircctly account for are now much more effective. The mirror errors are about one third the total, while in Table III. they are more than two thirds.

7. The errors, barring those of a single observer, show no tendency to concentration in either hand.

\section{TABLE V.}

Two Mirrors, in Front and Below. Supination. Fingers Clasped OVER BACKS OF HANDS.

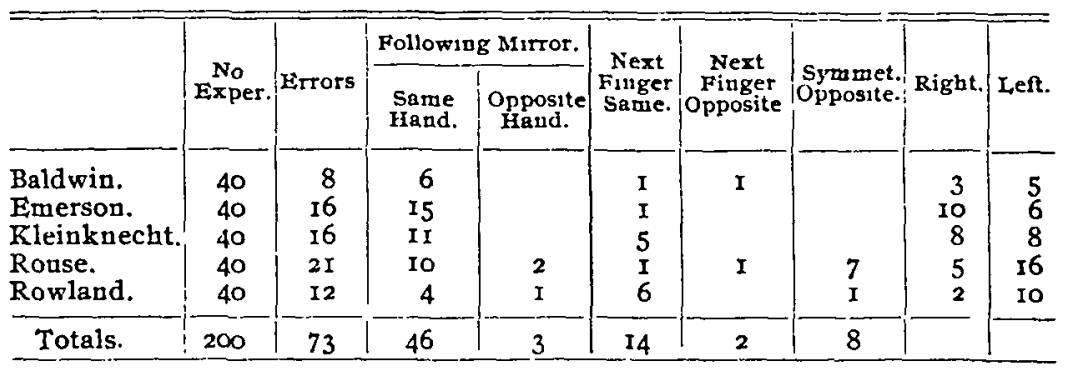

TABle VI.

Two Mirrors, in Front and Below. Pronation. Fingers Clasped IN PALMS.

\begin{tabular}{|c|c|c|c|c|c|c|c|c|c|}
\hline & \multirow{2}{*}{$\begin{array}{l}\text { No. } \\
\text { Exper }\end{array}$} & \multirow[b]{2}{*}{ Errors. } & \multicolumn{2}{|c|}{ Following Mirtor } & \multirow{2}{*}{$\begin{array}{l}\text { Nest } \\
\text { Finger } \\
\text { Same }\end{array}$} & \multirow{2}{*}{$\begin{array}{c}\text { Next } \\
\text { Finger } \\
\text { Opposite }\end{array}$} & \multirow{2}{*}{$\begin{array}{l}\text { Symmet. } \\
\text { Syposite. }\end{array}$} & \multirow{2}{*}{ Right } & \multirow[b]{2}{*}{ Left } \\
\hline & & & $\begin{array}{l}\text { Same } \\
\text { Hand. }\end{array}$ & $\overline{\text { Opposite }}_{\text {Hand }}$ & & & & & \\
\hline $\begin{array}{l}\text { Baldwin. } \\
\text { Emerson. } \\
\text { Kleinknecht. } \\
\text { Rouse. } \\
\text { Rowland. }\end{array}$ & $\begin{array}{l}40 \\
40 \\
40 \\
40 \\
40\end{array}$ & $\begin{array}{r}16 \\
11 \\
8 \\
26 \\
9\end{array}$ & $\begin{array}{r}10 \\
10 \\
5 \\
6 \\
4\end{array}$ & 7 & $\begin{array}{l}\text { I } \\
3\end{array}$ & I & $\begin{array}{r}3 \\
1 \\
2 \\
10 \\
5\end{array}$ & $\begin{array}{l}6 \\
5 \\
6 \\
7 \\
4\end{array}$ & $\begin{array}{r}10 \\
6 \\
2 \\
19 \\
5\end{array}$ \\
\hline Totals. & 200 & 70 & 35 & 8 & 5 & I & $2 \mathrm{I}$ & & \\
\hline
\end{tabular}

8. What is the cause for the great difference in the amount of illusion between Tables III. and IV.? A suggestion readily occurring would attribute it to the greater ease of recognizing the fingers as individuals when they are clasped over the backs of the hands. In support of this view may be cited the results of some experiments performed on Rouse. The conditions differed from those of Table IV. in this, that the fingers were covered with paper rolls that largely concealed their individual 
characteristics. In the same number of experiments his errors were three times as many; and more than two thirds of these followed the mirror reversal. And these results were obtained a week after the former, so that the former results do not appear to have been due to practice.

But we shall find in Tables V. and VI. evidence to show us that the positions of pronation or supination can importantly modify the illusion; and so to these factors in the present case we shall have to allow some influence.

For the experiments of Table V. two mirrors were used, at right angles to each other; one flat, the other perpendicular to the median plane of the observer. The fingers were clasped in the manner indicated by the tables and directed downward, so that the observer looking into the upright mirror could see a reflection of the image of the flat mirror. A cloth over the top of the upright mirror prevented a direct reflection of the hands in it. The image as seen by the observer reversed the real position of pronation or supination and also, as in the preceding experiments, the halves of each hand. In all essentials the conditions of Table $V$. resemble those of Table IV., the conditions of Table VI. those of Table III., except in pronation and supination.

\section{REsults.}

I. The total amount of errors is greater in the position of supination than of pronation. In other words, the pronated hand appears to be under better control. The results of Miller have to be excluded from Table III. in order to make a justifiable comparison. Specifically stated, the errors for Table V., (supination) are more than double those in Table IV. (pronation). A comparison of Tables III. and VI. yields similar results.

2. Again the errors find a second center in Table V., in the fingers next to the one indicated and on the same side; while in Table VI., this second center is rather in the finger symmetrically opposite.

3. The tendency of the movement to follow the visual cue is still evident. 
ABNORMAL POSITION AND MOTOR IMPULSE. $\quad 3^{8 \mathrm{I}}$

\section{TABLE VII.}

A. Mirror Front. LefT PalM UP. Right Down.

\begin{tabular}{|c|c|c|c|c|c|c|c|c|c|c|c|}
\hline & \multirow[b]{2}{*}{ 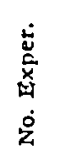 } & \multirow[b]{2}{*}{ 量 } & \multicolumn{3}{|c|}{ Followiug Mirror } & \multirow[b]{2}{*}{ 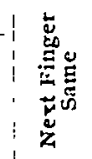 } & \multirow[b]{2}{*}{ 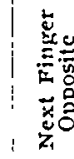 } & \multirow[b]{2}{*}{ 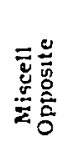 } & \multirow[b]{2}{*}{ 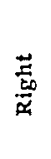 } & 1 & \multirow[b]{2}{*}{ تِّت } \\
\hline & & & 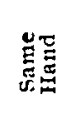 & 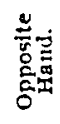 & 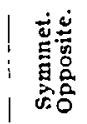 & & & & & 1 & \\
\hline Baldwin. & & 28 & 16 & I & 5 & 5 & í & I & 13 & & 15 \\
\hline Boswell. & $72^{1}$ & $3 \mathrm{I}$ & 20 & & 5 & 3 & 2 & I & 5 & & 26 \\
\hline Emerson. & 40 & 17 & II & & 2 & 2 & & & 6 & & I I \\
\hline Holt. & 24 & 13 & I 2 & & & I & & & 2 & & II \\
\hline Kleinknecht. & 24 & 4 & 3 & & & I & & & I & & 3 \\
\hline Rouse. & 48 & 35 & 22 & & I & 10 & 2 & & 17 & & IS \\
\hline Rowland. & 48 & IS & 9 & & & 3 & 1 & & 3 & & I5 \\
\hline Miller. & 48 & 26 & 16 & & 4 & 4 & 2 & & 9 & & 17 \\
\hline Totals. & 352 & I72 & 109 & $\mathbf{I}$ & I7 & 29 & 12 & 2 & & & \\
\hline
\end{tabular}

B. As ABove, ExchPT RIght PALM UP, LEFT DOWN.

\begin{tabular}{|c|c|c|c|c|c|c|c|c|c|c|c|}
\hline Baldwin. & 48 & I5 & 8 & $\mathbf{I}$ & 2 & 2 & 2 & & I I & & 4 \\
\hline Boswell. & $72^{1}$ & 37 & 20 & I & 5 & II & & & II & & 7 \\
\hline Emerson. & 40 & 13 & II & & & 2 & & & 9 & & 4 \\
\hline Holt. & 24 & 15 & 13 & & I & I & & & 7 & & 8 \\
\hline Kleinknecht. & 24 & 5 & I & & 2 & 2 & & & 4 & & I \\
\hline Rouse. & 48 & $3 I$ & 21 & & 4 & 4 & 2 & & 19 & & 12 \\
\hline Rowland. & 48 & 29 & II & I & 9 & 3 & 3 & 2 & 14 & & I5 \\
\hline Miller. & 48 & $2 \mathrm{I}$ & 9 & & & & 2 & & I 3 & & 8 \\
\hline Totals. & 352 & 166 & 94 & 3 & 29 & 29 & 9 & 2 & & i & \\
\hline
\end{tabular}

TABLE VIII.

A. MirRor Front. Direction of Fingers Opposite IEFT FaIM t'P, RIGHT DOWN.

\begin{tabular}{|c|c|c|c|c|c|c|c|c|c|c|c|}
\hline & \multirow[b]{2}{*}{$\begin{array}{l}\dot{d} \\
\frac{d}{\alpha} \\
\dot{\alpha} \\
\dot{z}\end{array}$} & \multirow[b]{2}{*}{ 喝 } & \multicolumn{3}{|c|}{ Follow2ng Mirror } & \multirow{2}{*}{ 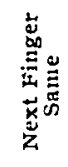 } & \multirow[b]{2}{*}{ 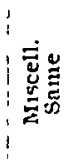 } & \multirow[b]{2}{*}{ 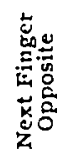 } & \multirow[b]{2}{*}{ 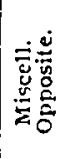 } & \multirow[b]{2}{*}{ 咅 } & \multirow[b]{2}{*}{ 竎 } \\
\hline & & & 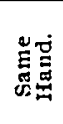 & 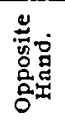 & 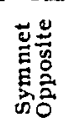 & & & & & & \\
\hline Baldwin. & 40 & 25 & 23 & I & I & & 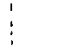 & $I$ & & 8 & 17 \\
\hline Klein knecht. & 40 & 7 & 4 & & & & & 3 & & 7 & \\
\hline Rouse. & 40 & 22 & I3 & I & 3 & 4 & & I & & 8 & I4 \\
\hline Rowland. & 40 & I 8 & I 2 & $\mathbf{I}$ & I & 2 & ! & 2 & & 3 & I5 \\
\hline Totals. & 200 & 90 & 69 & 3 & 5 & 6 & & 7 & & & \\
\hline
\end{tabular}

B. As ABove, EXcept Right PALM Up, Left Down.

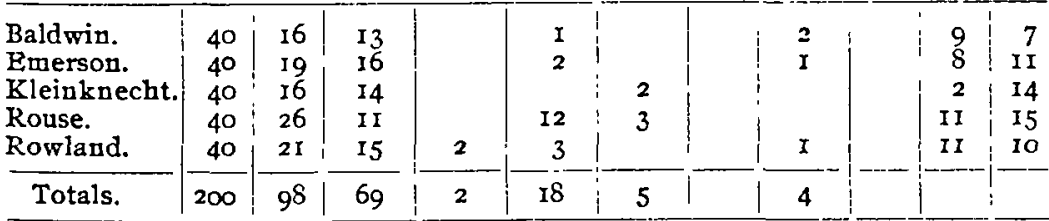

'These results are combined from the work of two days, agreeing in tendercy. 
TABLE IX.

A. Mirror front. Caps on Paim-down fingers. Left Palm Up, RIGHT DOWN.

\begin{tabular}{|c|c|c|c|c|c|c|c|c|c|c|c|}
\hline & \multirow{2}{*}{ 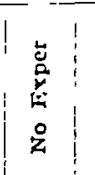 } & \multirow{2}{*}{ 点 } & \multicolumn{3}{|c|}{ Following Mirror. } & \multirow[b]{2}{*}{ 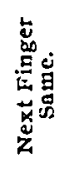 } & \multirow{2}{*}{$\mid$} & \multirow{2}{*}{ 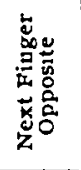 } & \multirow{2}{*}{ 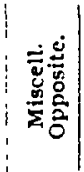 } & \multirow[b]{2}{*}{$\frac{\vec{d}}{\overrightarrow{b c}}$} & \multirow[b]{2}{*}{ نيّ } \\
\hline & & & 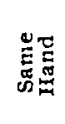 & 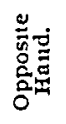 & 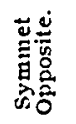 & & & & & & \\
\hline $\begin{array}{l}\text { Baldwin. } \\
\text { Emerson. } \\
\text { Kleinknecht. } \\
\text { Rouse. } \\
\text { Rowland. }\end{array}$ & $\begin{array}{l}40 ! \\
40 \\
40 \\
40 ! \\
40\end{array}$ & $\begin{array}{r}22 \\
8 \\
16 \\
24 \\
9\end{array}$ & $\begin{array}{r}15 \\
8 \\
12 \\
19 \\
8\end{array}$ & & 3 & $\begin{array}{l}4 \\
2 \\
\text { I }\end{array}$ & & 2 & & $\begin{array}{r}8 \\
1 \\
16 \\
13 \\
5\end{array}$ & $\begin{array}{r}14 \\
7\end{array}$ \\
\hline Totals. & $200 i$ & 79 & 62 & & 5 & Io & & 2 & & & \\
\hline
\end{tabular}

B. As Above, Except Right Pala Up, LeFt Down.

\begin{tabular}{|c|c|c|c|c|c|c|c|c|c|}
\hline $\begin{array}{l}\text { Bald win. } \\
\text { Emerson. } \\
\text { Rleinknecht. } \\
\text { Rouse. } \\
\text { Rowland. }\end{array}$ & $\begin{array}{l}40^{1} \\
40^{1} \\
40 \\
40 \\
40\end{array}$ & $\begin{array}{l}22 \\
13 \\
13 \\
24 \\
23\end{array}$ & $\begin{array}{r}18 \\
11 \\
7 \\
18 \\
20\end{array}$ & $\begin{array}{l}3 \\
1\end{array}$ & $\begin{array}{l}3 \\
2 \\
3 \\
4 \\
1\end{array}$ & $\begin{array}{l}\mathrm{I} \\
\mathbf{2}\end{array}$ & I & $\begin{array}{r}12 \\
9 \\
4 \\
8 \\
9\end{array}$ & $\begin{array}{r}10 \\
4 \\
9 \\
16 \\
14\end{array}$ \\
\hline Totals. & 200 & 95 & 74 & 4 & I3 & 3 & I & & \\
\hline
\end{tabular}

\section{Table X.}

A. Mirror Front. Caps on Ale Fingers. Lett Palm Up, Right Down.

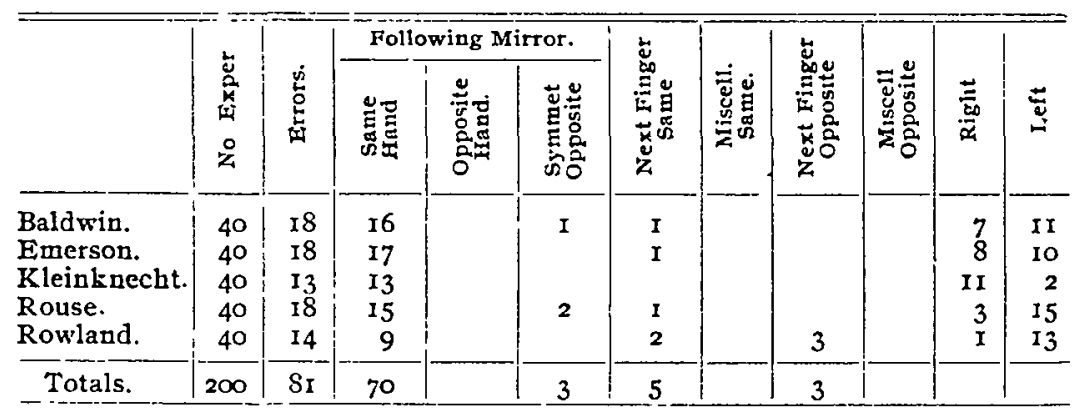

B. As Above, Except Right Palm Up, LeFt Down.

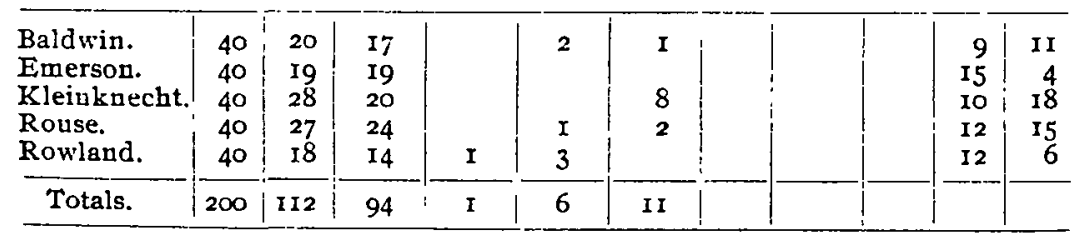

${ }^{2}$ Results obtained at two sittings but accordant. 
A further test of the influence of pronation and supination, as well as of the visual position of the members, was devised in these new experiments.

The conditions belonging to them are the following: The line of the crossed fingers is again perpendicular to the mirror plane; but the clasped hands are one in the position of pronation, the other in that of supination. The differences among these four sets are the result of an attempt to eliminate the factors that might be responsible for the tendency to mass failures in a given hand. So in Table VIII. care was taken that the fingers of the supinated hand should not be allowed to curl up, as they are inclined to do; but should maintain their direction as steadily as do the fingers of the other hand. In Table IX. the attempt was made to check the one-sidedness that might well grow out of the greater ease in recognizing fingers whose backs are in view, by covering those fingers with caps made in the form of paper tubes. And these coverings were extended to the fingers of both hands in Table $X$., as equalizing most fairly the conditions for both. Here also the effort was made to maintain the opposition in direction of the fingers. Finally, the same number of experiments was performed with each hand in a given position.

\section{RESULTS.}

I. There appears at first sight to be no simple relation between the conditions studied and the tendency to mass failures in one hand. Looking further, however, we find that while frequently there is no such tendency, yet when it does occur, the drift is to the supinated hand. Cf. Table XI. One observer is a definite and consist exception.

2. This must be at least relatively independent of ease in recognizing the fingers, since it occurs even when the caps are on both hands.

3. Tables VII. and VIII. show a massing of erroneous movements on the symmetrically opposite finger, as well as on the next fingers of both the same and the opposite sides. This tendency to a confusion of hands cannot be accounted for as a case of mirror reversal. In Tables IX. and X., there is no such drift upon the symmetrically opposite finger, but the next fingers on the same side are chiefly favored. 
4. In general, the distribution and the significance of the errors here agree with Tables III. and IV. A test of the fingers in this position under the condition of direct vision showed practically complete control.

TABLE XI.

SUMMARY OF TABLES VII.-X.

\begin{tabular}{|c|c|c|c|c|c|c|c|c|c|c|c|c|}
\hline & \multicolumn{3}{|c|}{ Tabie VII } & \multicolumn{3}{|c|}{ Table viII. } & \multicolumn{3}{|c|}{ Table $\mathbf{L X}$. } & \multicolumn{3}{|c|}{ Table $\mathrm{X}$} \\
\hline & 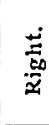 & J & $\begin{array}{l}\dot{\vec{u}} \\
\text { 䓪 } \\
\dot{8}\end{array}$ & $\underset{\dot{z}}{\dot{\vec{x}}}$ & $\stackrel{\Xi}{\leftrightarrows}$ & 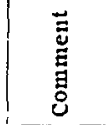 & $\underset{\not \alpha}{\stackrel{\infty}{*}}$ & 岀 & $\begin{array}{l}\dot{\vec{z}} \\
\text { 昱 } \\
\dot{8}\end{array}$ & 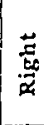 & 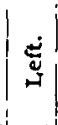 & 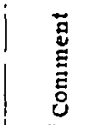 \\
\hline Baldwin. & 13 & I5 & & 8 & I7 & 1. up & 8 & 14 & 1. up & 7 & II & \\
\hline & II 6 & 4 & r. up & 9 & 7 & & 12 & 10 & & 9 & II & \\
\hline Emerson. & $\begin{array}{l}0 \\
9\end{array}$ & II & 1. & $\begin{array}{l}8 \\
8\end{array}$ & Io & & I & 7 & 1." " & 8 & I0 & r. vo \\
\hline \multirow{2}{*}{ Kleinknecht } & I & 3 & & 7 & & r. down & 16 & & r. down & $\begin{array}{l}11 \\
15\end{array}$ & $\begin{array}{l}4 \\
2\end{array}$ & r. down \\
\hline & 4 & I & & 2 & I4 & & 4 & 9 & 1." & 10 & 18 & \\
\hline \multirow[t]{2}{*}{ Rouse. } & 17 & I8 & & 8 & 14 & 1. up & I3 & II & & 3 & 15 & 1. up \\
\hline & 19 & I 2 & r. " & I I & I5 & & $\overline{8}$ & 16 & 1. down & 12 & I5 & \\
\hline Rowland. & $\begin{array}{r}3 \\
14\end{array}$ & $\begin{array}{l}\text { I5 } \\
15\end{array}$ & $1 . "$ & 3 & I5 & 1. " " & 5 & 4 & 1. " & 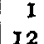 & 13 & 1. " “ \\
\hline Boswell. & 5 & 26 & 1. “" & & & & & & & & & \\
\hline Holt. & 2 & II & 1." " & & & & & & & & & \\
\hline Miller. & 9 & $\begin{array}{r}8 \\
17\end{array}$ & 1." " & & & & & & & & & \\
\hline nuner. & & & & & & & & & & & & \\
\hline
\end{tabular}

Against the significant differences in Table XI. is indicated the hand that was supinated. All the observers, except Kleinknecht agree in concentrating failures, if anywhere, in the hand whose palm is up. There are but two exceptions in the twentytwo cases. Kleinknecht is just as constant in the opposite direction and furnishes a larger number of significant cases than does any other observer. Why the cause operating in the other observers should produce intermittent effects does not so far appear.

The conditions prevailing in these new experiments were calculated to increase yet more the influence of the abnormal visual position of the fingers. Two mirrors were set together at an angle of about $90^{\circ}$. The observer sat over against the apex of the angle thus formed, and his clasped hands lay in the region embraced by the angle of the mirrors. The manner of clasping the hands is shown in the table. The fingers were 
TABLE XII.

A. Two Mirrors, Right-IfeFr, Caps on all, Fingers, lefí palm Up, RIGHT DOWN.

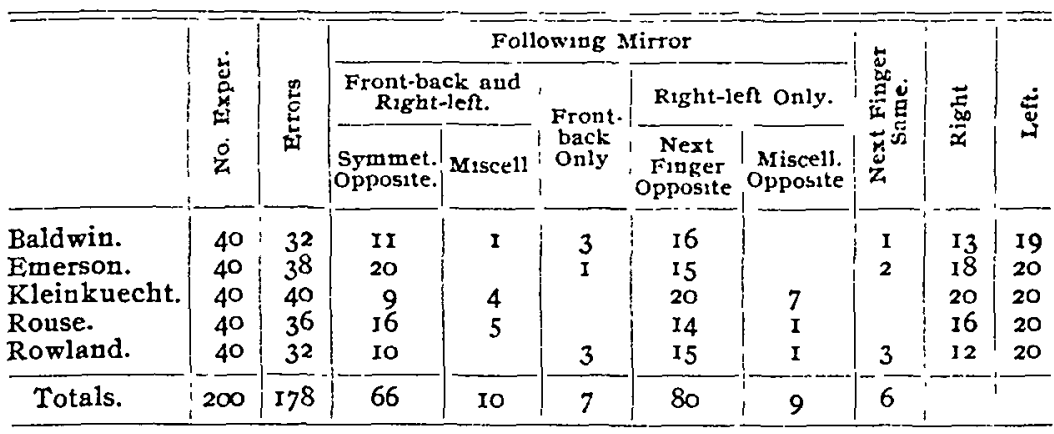

B. AS ABove, EXCEPT RIGHT PALM UP, LEFT DOWN.

\begin{tabular}{l|c|c|c|c|c|c|c|c|c|c}
\hline Baldwin. & 40 & 29 & 9 & I & II & 7 & & 1 & 17 & 12 \\
Emerson. & 40 & 40 & 20 & 3 & 2 & 15 & & & 20 & 20 \\
Kleinknecht. & 40 & 39 & 18 & 3 & I & 16 & & I & 20 & 19 \\
Rouse. & 40 & 39 & 22 & 3 & 3 & 9 & 2 & & 19 & 20 \\
Rowland. & 40 & 34 & 17 & I & II & 4 & 1 & & 15 & 19 \\
\hline \multicolumn{1}{c|}{ Totals. } & 200 & 181 & 86 & II & 28 & 51 & 3 & 2 & & \\
\hline
\end{tabular}

disguised with the usual caps. The observer looked into the right mirror to see the reflection of the image as originally given in the left mirror. The second mirror gave a right-left as well as a front-back reversal of the real position of the fingers. The hands were so placed that but little could be seen of any primary images.

Results.

I. The very large proportion of errors shows the strength of the illusion.

2. This amount is so great that there is little chance to mass errors in either hand. The three cases where there is such a tendency conform to the chief type in Table XI.

3. The predominance of wrong movements is in the symmetrically opposite finger and those fingers in the opposite hand that lie next to the indicated finger. These are exactly the places where one would expect the wrong movement to be made. Where a new adjustment is made for the front-back reversal, the observer knows where on his hand the finger lies that he would move, but he mistakes the hand. Where a new 
adjustment is affected for neither reversal, the observer knows where in a given half of the hand the movement should be made, but he confuses both halves and hands.

\section{TABLE XIII.}

A. Mirror Front. Back of left hand against Palm of Right. Caps on Ali Fingers.

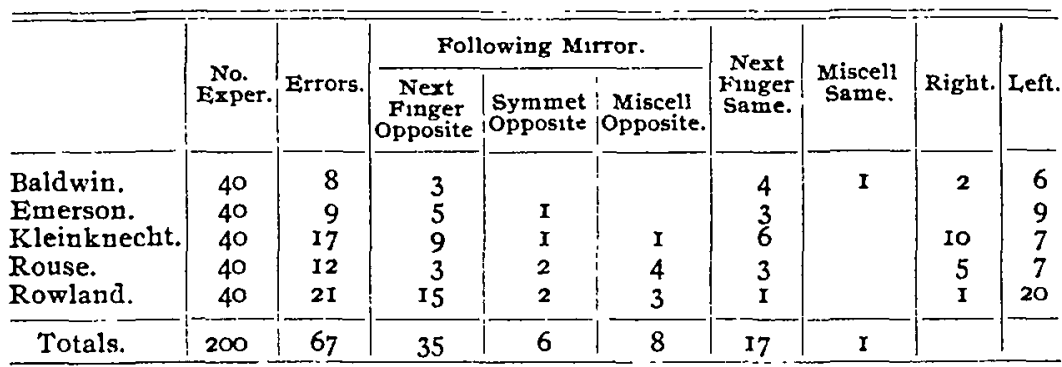

B. As ABOVH, EXCEPT REVHRSED RELATION OF HANDS.

\begin{tabular}{l|r|r|r|r|r|r|r|r|r}
\hline Baldwin. & 40 & 9 & 3 & & & 4 & 2 & 5 & 4 \\
Emerson. & 40 & 14 & 12 & & & 2 & & 2 & 12 \\
Kleinknccht. & 40 & 19 & 12 & 4 & & 3 & & 5 & 14 \\
Rouse. & 40 & 16 & 5 & 4 & 2 & 5 & & 8 & 8 \\
Rowland. & 40 & 15 & 8 & 6 & & 1 & & 3 & 12 \\
\hline Totals. & 200 & 73 & 40 & 14 & 2 & 15 & 2 & & \\
\hline
\end{tabular}

TABLE XIV.

A. MIRror $\angle 20^{\circ}$ RIght.

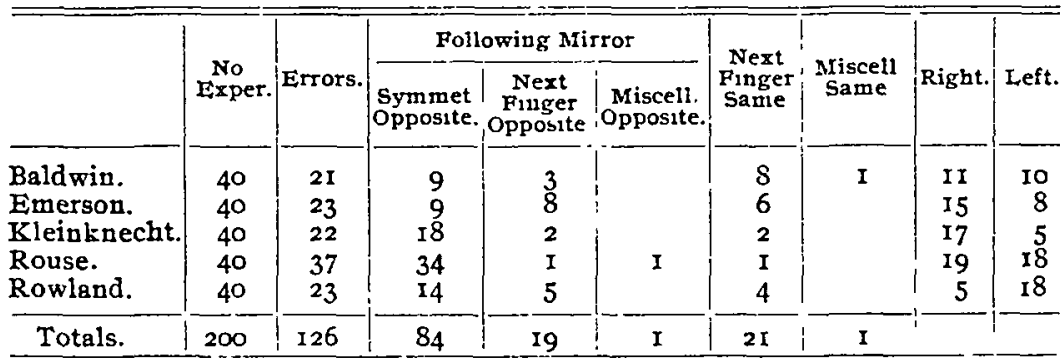

B. MirRor $\angle 20^{\circ}$ LEFT.

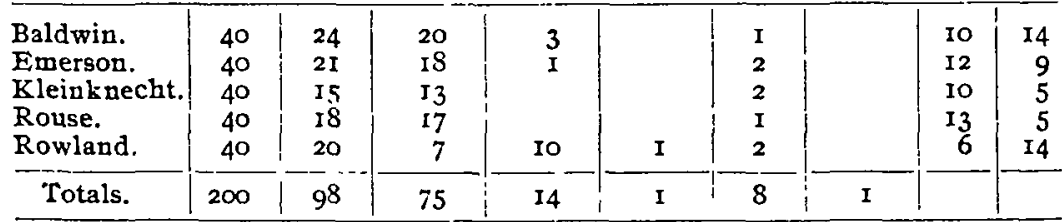


4. The difference in the amount of errors for the front-back and the right-left illusion indicates that adjustment to the former is much more easily effected. Our practical use of mirrors helps us to overcome the first illusion. The second sort of experience is relatively novel.

5. The number of errors that cannot be directly accounted for by the influence of the visual position is nearly negligible.

6. The right-left illusion is stronger when the left palm is up; the front-back illusion, when the right palm is up.

The conditions of the experiments in these tables were arranged to show the general principle of visual control, hitherto copiously illustrated, in yet further ways. For Table XIII., the hands are placed back against palm, the fingers interlocked, with the little fingers on the outside, and the line of the fingers parallel to the plane of the mirror set up in front. In the experiment of the other table the fingers were clasped palm up, the line parallel to the median plane of the body. The mirror was placed at an angle of about $20^{\circ}$ with the median plane. This angle was made as small as possible consistent with a convenient view on the part of the observer. The arrangements in both these cases were to reverse in appearance the position of the hands with reference to each other.

It should be said of the first set of experiments that the position chosen was so difficult a one that it was nearly impossible to keep each set of fingers in lines parallel to each other and to the mirror. Such displacements tended to produce reversals among the fingers of a single hand. This probably accounts, in part at least, for the erroneous movements made with the correct hand, though these are certainly not in excess of similar errors in Table XIV., where such an explanation is not possible.

The caps were used in Table XIII. because the clasped fingers did not symmetrically correspond, and the resulting differentiation, if seen, might lessen the illusion. This reason did not hold in Table XIV.

\section{Results.}

I. The expected illusion occurs in both cases.

2. The heaping of errors in Table XIV. on the finger sym- 
metrically opposite, and in the other table upon those fingers of the opposite hand that lie next to the indicated finger, is due in both cases to the same cause, viz., their occurrence in parts of the opposite hand spatially corresponding to the indicated finger.

3. The noticeable tendency in Table XIV. to a movement of the next fingers, either on the same or the opposite side, confirms earlier results; and we have already seen (conclusion 5 under Table I.) that the error cannot be set down wholly to resemblance.

Table XV.

SUMMARY.

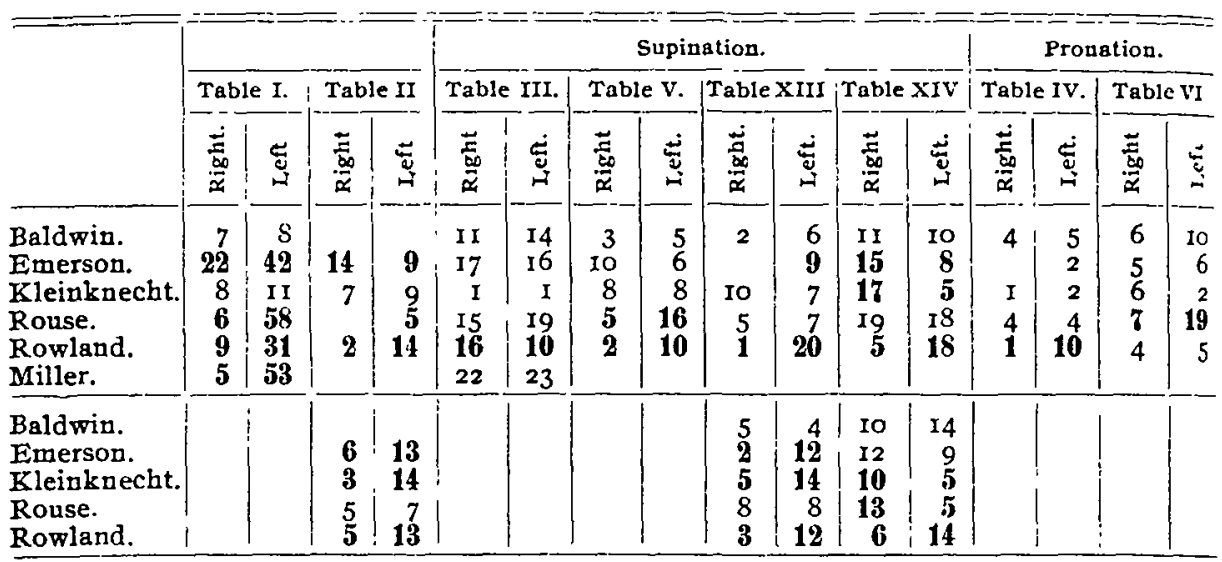

Table XV. presents a summary view of the failures to make the correct movement as these appear in the right and the left hands. All the tables are included where both hands agree in pronation or supination. This particular condition, as it is found in the unsymmetrical relation of the hands, has already been discussed in connection with Table XI. Here the results for Tables I., II., XIII. and XIV. fall into one group, as being concerned with an illusion that tended to throw the movement over to the opposite hand; while the remaining results were obtained where the illusion tended to divert the movement to the opposite side of the same hand. Tables III., V., XIII. and XIV. are concerned with positions of supination, and Tables IV. and VI. with pronation. For Tables I. and II, the position is a combination of both. 
Results.

I. The tendency to mass errors, where it occurs at all, shows a drift toward the left. Of twenty-six instances, twenty are of this type and six of the opposite type. Four of the latter are confined to one table (Table XIV.).

2. The existence of such a tendency seems to be connected with the illusion that throws the erroneous movement over to the opposite hand. Twenty-one instances occur in Tables I., II., XIII. and XIV., where the illusion is of this type. The remaining five are scattered through the other four tables.

\section{TABLE XVI.}

COMPLED FROM EXPERIMENTS EMBODIED IN TABLES VII. AND X.

\begin{tabular}{|c|c|c|c|c|c|c|c|c|c|}
\hline & & & rone & No & & & & & \\
\hline & & 2 & 3 & 4 & 5 & 2 & 3 & 4 & 5 \\
\hline Baldwin. & Right. & 4 & I & $2 I$ & 5 & 12 & I3 & 2 & 6 \\
\hline Bald win. & Left. & 6 & II & 24 & 7 & I5 & I 7 & 8 & 6 \\
\hline Emerson. & R. & 2 & 4 & $2 \mathrm{I}$ & Io & I5 & $\mathrm{Y} 7$ & 5 & 2 \\
\hline & L. & & & 24 & I3 & I5 & 18 & I & I \\
\hline Kleinknecht & R. & IO & Io & 6 & I & 4 & $I$ & 12 & I3 \\
\hline & L. & 9 & I5 & 2 & 7 & 10 & 4 & 10 & 10 \\
\hline Rouse. & R. & 10 & 8 & I I & I3 & I2 & 5 & 10 & 7 \\
\hline & $\pi$ & 18 & 16 & 7 & 10 & 16 & 5 & 19 & I9 \\
\hline Rowland. & R. & 15 & 17 & 4 & 2 & 5 & & 12 & IO \\
\hline & L. & $2 \mathrm{I}$ & 6 & 3 & 3 & IO & 4 & 14 & 16 \\
\hline
\end{tabular}

The numbers at the heads of the columns indicate the fingers in order, beginning with the forefinger.

The interesting questions naturally occur whether there is any tendency (I) to make more erroneous movements with one finger than with another; and (2) whether more failures occur similarly. To answer these questions the eight hundred experiments of Tables VII. and X. were worked over to discover the distribution of errors and failures among the fingers. Table XVI. presents the details.

\section{Results.}

I. The several observers do show a preference among the fingers in erroneous movements and also a massing of failures but they disagree with each other.

2. The right and left hands show a somewhat remarkable agreement in distribution for any one observer. Out of the 
forty cases, there appear to be but five where the relative distribution in the two hands is markedly different.

\section{TABLE XVII.}

TO SHOW DRIFT OF ERRORS TOWARD THOMB OR IITTLE FINGER.

\begin{tabular}{|c|c|c|c|c|c|c|c|c|c|c|c|c|c|c|}
\hline & \multicolumn{2}{|c|}{ Table III } & \multicolumn{2}{|c|}{ Table v } & \multicolumn{2}{|c|}{ Table vir. } & \multicolumn{2}{|c|}{ Table VIII. } & \multicolumn{2}{|c|}{ rable IX. } & \multicolumn{2}{|c|}{ Table $\mathrm{X}$} & \multicolumn{2}{|c|}{ Table XII. } \\
\hline & I. & $\mathbf{v}$ & I. 1 & $\nabla$. & I. I & v. & I & $\mathbf{v}$ & I & $\mathrm{v}$ & I! & v. & I. & v. \\
\hline $\begin{array}{l}\text { Kleinknec } \\
\text { Rouse. } \\
\text { Rowland. }\end{array}$ & $\begin{array}{l}1 \\
20 \\
13 \\
13\end{array}$ & $\begin{array}{r}I \\
I 3 \\
3\end{array}$ & $\begin{array}{l}15 \\
12 \\
10\end{array}$ & $\begin{array}{l}I \\
2 \\
I\end{array}$ & $\begin{array}{r}4 \\
46 \\
22\end{array}$ & $\begin{array}{r}4 \\
15 \\
13\end{array}$ & $\begin{array}{l}19 \\
17 \\
27\end{array}$ & $\begin{array}{r}4 \\
16 \\
8\end{array}$ & $\begin{array}{l}17 \\
30 \\
23\end{array}$ & $\begin{array}{r}9 \\
14 \\
9\end{array}$ & $\begin{array}{l}27 \\
25 \\
25\end{array}$ & $\begin{array}{r}14 \\
17 \\
4\end{array}$ & $\begin{array}{l}40 \\
24 \\
29\end{array}$ & $\begin{array}{l}\text { I2 } \\
\text { I3 } \\
\text { Io }\end{array}$ \\
\hline Totals. & 34 & I 7 & 37 & 4 & 72 & 32 & 63 & 28 & 70 & 32 & 77 & 35 & 93 & 35 \\
\hline $\begin{array}{l}\text { Emerson. } \\
\text { Baldwin. }\end{array}$ & $\begin{array}{r}12 \\
2\end{array}$ & $\begin{array}{l}\text { I7 } \\
21\end{array}$ & $\begin{array}{l}5 \\
6\end{array}$ & $\begin{array}{r}\text { II } \\
2\end{array}$ & $\begin{array}{l}\text { IO } \\
\text { I3 }\end{array}$ & $\begin{array}{l}16 \\
23\end{array}$ & $\begin{array}{r}1 \\
14\end{array}$ & $\begin{array}{l}34 \\
25\end{array}$ & $\begin{array}{r}4 ! \\
19 !\end{array}$ & $\begin{array}{l}17 \\
23\end{array}$ & 5 & $\begin{array}{l}32 \\
29\end{array}$ & $\begin{array}{l}16 \\
18\end{array}$ & $\begin{array}{l}22 \\
23\end{array}$ \\
\hline Totals. & 14 & 38 & II & I3 & 2.3 & 39 & 15 & 59 & 23 & 40 & II & $6 \mathrm{I}$ & 34 & 45 \\
\hline
\end{tabular}

Of the Roman numerals at the heads of the columns I. means thumb and V. little finger.

Table XVII. presents a new analysis of the results of the tables summarized therein. All the erroneous movements that were not made with the symmetrically opposite finger were classified on the principle of their occurrence either thumbward or toward the little finger from the indicated finger or its symmetrically opposite fellow. The observers were distributed so evenly between the two classes that they are separated in the table into two groups. Those of the former tables are included in this survey that showed the largest amount of errors falling elsewhere than on the finger symmetrically opposite.

\section{Results.}

I. The observers fall into two opposing groups, each showing a very consistent tendency of its special type, and one a very large one.

2. Considering each observer separately, we find that in one case only is there a direct contradiction of type, while in but three cases is neutrality almost or quite complete.

In what direction are we to look for an explanation of the facts that have come forward in the course of these experiments? In the first place, there is the fact of the existence of an illusion connected with an abnormal position of the members. We 
found this to be due in nearly every case to the abnormal visual factors, since their removal destroyed the illusion. A single observer in the Japanese illusion seemed to show that abnormal kinæsthetic factors were involved in producing it. We have to do here with a special case of neural habit. Visual cues and, more rarely, kinæsthetic cues have become in practice the welldefined guides of movement, to such an extent, indeed, that when these become untrustworthy through a change of conditions, it is only by effort, more or less, that the movement normally connected with them is prevented from occurring.

This principle seems to be illustrated yet further in our results. It appears that adjustments seeming equally easy to both hands in normal positions are less easy for the left than for the right when the positions are abnormal, as in our experiments, though the hands agree in position; and it appears further that for the supinated hand the adjustment is also more difficult. In other words, the neural habits underlying our practice in the control of our movements are primarily adjusted to a given space relationship of members; while plasticity is greater for the right hand than for the left, and for either hand pronated than supinated, though in the latter case we must not forget that for one observer just the reverse was true. The foregoing difference between the right and the left hands seems to be in line with the greater ease in control of the right that we find in many normal movements, though in the one we have investigated that difference had disappeared, yet only to reappear, as reversion to an earlier type, under the condition of abnormal position. This greater adjustibility in one half of the brain than in the other half we can view as related to practice. A similar account is possibly justifiable for the better control of the pronated hand, though we have still to dispose of our consistent exception. One is tempted to formulate a hypothesis along the familiar lines of the 'sensory' and 'motor' types, thereby saving our main principle in this case. For example, let us make the following suppositions: (I) Less vivid sensations represent our limbs in consciousness when they are normally than when abnormally disposed. (2) In the character of the motor discharge either the nature of the incoming currents 
or the situation of the centers may be prepotent. If the nature of the incoming current prevails, then the less familiar the situation the better the adjustment, and vice versa; but if the situation of the centers prevails, then the more familiar the outward situation, the more correct the response. The former is the 'sensory' type, in which must be classified the single observer whose control is best over the supinated hand; while the rest of the observers belong to the latter or 'motor' type.

The tendency of the erroneous movement to be drawn toward either the thumb or the little finger, according to the type, may be due to the more habitual employment of the members that lie on a given side. The difficulty with this view is that one would expect all erroneous movements to be drawn thumbward, since that side is probably in all but rare cases the stronger. Individual tendencies to favor or fail in a giren finger have probably a share in the explanation accorded to the foregoing fact.

We have reason to believe that resemblance plays some part in the drift of erroneous movements toward the finger symmetrically opposite; but the amount of this error when the fingers are disguised with caps suggests the existence of an additional factor, perhaps purely physiological. In this direction points also the prominence of the fingers next to this and to the indicated finger in wrong movements; for we found in the discussion of Table I. that resemblance as a complete account of this case was out of the question. The precise nature of this additional factor is obscure to the writer.

There is further obscurity about the connection between the prevalence of failures in a given hand and the presence of an illusion that tends to throw the movement over to the opposite hand. The strength of the evidence for such a connection we saw in Table XV.

\section{Summary.}

I. The influence of abnormal position upon the motor impulse, under the conditions of these experiments, is to change its direction in certain well-defined ways (cf. all tables).

2. There is a strong tendency to move the finger that really is where the indicated finger appears to be (cf. all tables). 
3. That visual factors control the movement is shown by the disappearance of the illusion when touch is added to vision, or where vision is excluded and the stimulus is auditory. Its failure to disappear in the latter case for one observer shows that occasionally abnormal kinæsthetic factors can rise to importance (cf. discussion under Table I.).

4. There is a greater tendency to a wrong direction of the impulse if the indicated movement is to be made (I) with the left hand (Table XV.), and (2) with the supinated hand (Table XI.). A single observer out of eight is pretty consistently of the opposite type in (2).

5. This tendency to mass failures in a given hand is not due to the greater difficulty of recognizing as individuals the fingers of that hand. Cf. Tables VII.-X.

6. In the case of the Japanese Illusion, it is not due to a greater strain on one wrist than on the other. Cf. Table II.

7. The prevalence of failures in the right or the left hand seems to depend upon the conditions favoring that form of the illusion that throws the movement over to the other hand (Table XV.).

8. Individual observers are inclined to favor particular fingers in erroneous movements and to fail more frequently in control of one finger than of another; but among themselves the observers are very divergent (Table XVI.).

9. There are subordinate tendencies to move: (I) The fingers next to the indicated finger on the same hand; (2) the symmetrically opposite finger, and (3) the fingers next to the latter (cf. all tables).

10. The tendencies described in (I) and (3) above are not due to the resemblances between the correct and the wrong finger. An examination of the results in Table I. showed that the middle and ring fingers, which resemble each other most of all, were not mistaken for each other with more significant frequency than the thumb and forefinger.

II. There is a further tendency for wrong movements to be drawn toward the thumb side of the hand, in the case of three observers, and toward the little finger in the other two (Table XVII.). 
I2. The existence of the illusion is based on the law of neural habit. Our habitual dependence upon the visual cue in controlling our movements leads us astray when that cue no longer truly represents the actual situation. Failures are more frequent in the left hand because finer adjustments are less habitual to it. For that reason they are more frequent in the position of supination. The condition of the centers is prepotent in determining the reaction. In the exceptional type in which failures occur more frequently in pronation, the reaction may be viewed as determined chiefly by the incoming currents Here the less familiar the situation, the more vivid the accompanying sensations and the better the adjustment. In the former, the more familiar the situation, the more correct the response. For the other facts in this summary, I can give no explanation.

The observers taking part in the work were students in the Harvard Psychological Laboratory, one being an instructor. Of the number, two were women and six were men. I acknowledge most heartily their coöperation, as well as that of Professor Münsterberg, to whom I owe the suggestion of the problem. ${ }^{1}$

${ }_{1}^{1}$ The MSS. of this article was received April 14, 1904.-Ed. 